\title{
Expression profiling of androgen-dependent and -independent LNCaP cells: EGF versus androgen signalling
}

\author{
Josien K Oosterhoff, J Anton Grootegoed and Leen J Blok
}

Department of Reproduction and Development, Erasmus MC, Erasmus University Rotterdam, PO Box 1738, 3000 DR Rotterdam, The Netherlands

(Requests for offprints should be addressed to L J Blok; Email: I.blok@erasmusmc.nl)

\begin{abstract}
Prostate cancer development often includes a shift from androgen-dependent to androgenindependent growth. It is hypothesized that, during this transition, growth factors like the epidermal growth factor (EGF) gain importance as activators of tumour cell proliferation. To study this, androgen- and EGF-regulation of growth and gene-expression was analysed in the androgendependent human prostate cancer cell line LNCaP-FGC (FGC) and its androgen-independent derivative line LNCaP-LNO (LNO). It was observed that androgen-dependent FGC cells require exposure to either androgens or EGF to proliferate. This is in contrast to androgen-independent LNO cells that showed significant proliferation in medium depleted of androgens and growth factors. Gene expression data were obtained for the androgen-dependent FGC and androgen-independent LNO cells cultured in the presence or absence of androgens (synthetic R1881) or EGF for different time periods. Expression profiling showed that many cell cycle genes, including a number of androgen- and EGF-regulated genes, are constitutively activated in androgen-independent LNO cells. Furthermore, the overlap between changes in gene expression activated by androgen and EGF receptor signalling pathways was found to be very high (75\%). These results partly explain why androgen-independent LNO cells can proliferate in the absence of androgenic stimulation. However, possibly other, so far unknown, signal transduction pathways that induce and maintain proliferation, have also been activated.
\end{abstract}

Endocrine-Related Cancer (2005) 12 135-148

\section{Introduction}

Molecular mechanisms involved in the transition from androgen-dependent to androgen-independent prostate tumour growth have been the subject of research for many years. Candidate mechanisms involving the androgen receptor (AR) have been suggested, including mutations that activate AR transcriptional activity, over-expression of co-activators of the AR, and cross talk with other growth signalling pathways (Balk 2002, Shaffer \& Scher 2003). The focus of the present study is on the involvement of peptide growth factors, especially the epidermal growth factor (EGF), in the progression of prostate cancer.

Peptide growth factors are, next to androgens, essential for prostate growth and maintenance of prostate function (Russell et al. 1998). In normal prostate, peptide growth factors act in a paracrine manner; stroma cells produce growth factors which act on epithelial cells (Hayward et al. 1997). In prostate cancer, production of growth factors switches to an autocrine mode, where epithelial cells become stimulated to produce their own growth factors (Wong \& Wang 2000). In addition, growth factor signalling during prostate cancer progression is deregulated because the expression levels of several important growth factor receptors increase.

Djakiew and Russel extensively reviewed the involvement of many growth factors and their receptors in prostate cancer (Djakiew 2000, Russell et al. 1998). The EGF receptor has been reported to be expressed at a higher level in malignant prostate tissue compared 
with normal prostate (Scher et al. 1995, Di Lorenzo et al. 2002, Hernes et al. 2004). However, other investigators reported no change or even a decrease in EGF receptor expression (Robertson et al. 1994, Turkeri et al. 1994). Possible regulation of EGF and its receptor by androgens is also the subject of discussion. In normal prostate, androgens stimulate expression of EGF in stromal cells (Hiramatsu et al. 1988, Nishi et al. 1996), but in prostate cancer cells this is not observed (Connolly \& Rose 1990, Russell et al. 1998). Furthermore, it is not clear whether androgenic control of EGF receptor expression involves increased or decreased expression (Schuurmans et al. 1988, Fiorelli et al. 1991, Djakiew 2000, Di Lorenzo et al. 2002). Still, a detailed analysis of the changing pattern of expression of EGF and the EGF receptor during progression of prostate cancer did indicate that a switch from paracrine to autocrine EGF signalling can play a role in autonomous growth of androgenindependent prostate cancer cells (Scher et al. 1995).

The intracellular domain of the EGF receptor is a tyrosine kinase, which, upon ligand binding of the receptor, becomes activated to form a docking site for several cytoplasmic adaptor proteins (Wells 1999, Yarden 2001). These adaptors sequester proteins that stimulate different kinase cascades such as the MAP kinase cascade. As a result, newly phosphorylated proteins may directly affect cell growth, differentiation and migration independent of transcriptional regulation or may activate transcription factors that induce expression of genes that play a role in these processes (Garbay et al. 2000, Yarden 2001). The AR is a transcription factor that is activated by androgens and then translocates to the nucleus where the receptorligand complex regulates transcription of many genes involved in growth and maintenance of the normal prostate (Balk 2002, Gelmann 2002). It has been suggested that in androgen-independent prostate cancer the AR is activated by other substances than androgens (Grossmann et al. 2001). Since activation of the AR may involve phosphorylation (Brinkmann et al. 1999, Gelmann 2002) and the EGF signalling pathway activates MAP kinases, EGF-induced and androgenindependent activation of the AR seems a possibility. In fact, activation of the AR via MAP kinases by EGF, and also through HER2 another EGF receptor, has been reported (Culig et al. 1994, Yeh et al. 1999, Gregory et al. 2004).

The human prostate cancer cell line LNCaP-FGC (FGC) is a model for androgen-dependent growth. In the current study we show that this cell line indeed depends on androgen action for its growth. An important derivative of this cell line is the androgen- independent LNCaP-LNO (LNO) cell line, which was developed from cultures of an early passage of LNCaP-FGC (Horoszewicz et al. 1980, van Steenbrugge et al. 1991, Chang et al. 1997). These androgendependent FGC and androgen-independent LNO cell lines were investigated to establish the extent to which androgenic- and EGF-signalling become intertwined during the transition from androgen-dependent to androgen-independent prostate cancer growth. Furthermore, the possible involvement of other signalling pathways was investigated.

\section{Materials and methods}

\section{Materials and chemicals}

Cell culture flasks and plastic disposables were obtained from Fisher Scientific (Houston, TX, USA). RPMI 1640 and culture chemicals were purchased from GIBCO Invitrogen Corporation (Carlsbad, CA, USA). Fetal calf serum (FCS) was from Greiner (Frickenhausen, Germany), EGF from SIGMAAldrich Chemie BV (St Louis, MI, USA). R1881 (methyltrienolone) was purchased from NEN (Boston, MA, USA), AG1478 from Calbiochem (San Diego, CA, USA). Bicalutamide (ICI176.334, Casodex) was from AstraZeneca (Macclesfield, UK), and was freshly dissolved in ethanol prior to each use.

\section{Cell culture and treatment}

The LNCaP-FGC cells (FGC, passage number 22-30) were kindly provided to us by J S Horoszewicz (Millard Fillmore Hospital, Buffalo, NY, USA). Identical cells can be obtained from the American Type Culture Collection (Rockville, MD, USA). FGC cells were maintained at $37{ }^{\circ} \mathrm{C}$ in a humidified incubator containing 5\% $\mathrm{CO}_{2}: 95 \%$ air in RPMI 1640 supplemented with $200 \mathrm{IU} / \mathrm{ml}$ penicillin, $200 \mu \mathrm{g} / \mathrm{ml}$ streptomycin and 5\% v/v FCS. The LNO cell line has been derived from an early passage (sixth) of the parental FGC cell line (Horoszewicz et al. 1980). These cells were grown under the same conditions as their parental cells, except that the serum used was DCC-FCS, depleted of steroids by dextran-coated-charcoal treatment using $0.1 \%$ dextran and $1 \%$ charcoal (van Steenbrugge et al. 1991).

Before EGF or androgen treatment, LNCaP cells were deprived of androgens and most growth factors through $48 \mathrm{~h}$ culture in medium containing $5 \% \mathrm{v} / \mathrm{v}$ DCC-FCS and then treated with additional added EGF $(20 \mathrm{ng} / \mathrm{ml})$ or R1881 $(0.1 \mathrm{~nm})$ for various periods. Total RNA was extracted by lysing the cells with $3 \mathrm{M}$ lithium chloride/6 M urea (Chang et al. 1997). 


\section{Micro-array analysis}

In situ synthesized oligo microarray (Human 1A) containing over 22000 unique 60 -mer oligos representing over 17000 unique human genes, were used in these studies (Agilent, Palo Alto, CA, USA). For each hybridisation, $13 \mu \mathrm{g}$ of total RNA was used in a direct labelling protocol. The RNAs of the different time points were all hybridised on separate arrays, with the RNA of untreated cells as reference samples. Labelling, hybridisation, scanning procedures and data compiling was performed by ServiceXS, Leiden, The Netherlands (www.servicexs.com), with Agilents G2566AA Feature Extraction Software. The compiled experimental data were further analysed using the Microsoft Excel program (2000) and Rosetta Resolver Gene Expression Data Analysis System (Rosetta Inpharmatics LLC, Seattle, WA, USA). Gene annotations were done with GO-MAPPER, a locally developed annotation tool (Smid \& Dorssers 2004). The Database For Annotation, Visualization and Integrated Discovery (DAVID) (www.david.niaid.nih.gov/david/ ease.htm) was used for pathway discovery. Clusteranalysis was performed with Expression Profile Data CLUSTering and Analysis (EPCLUST) (www.ep.ebi. ac.uk/EP/EPCLUST).

\section{Cell growth study}

FGC and LNO cells were grown for 3 days on DCCFCS and then plated in 24 well plates $\left(4.10^{4}\right.$ cells $\left./ \mathrm{ml}\right)$. Three days after plating ( 0 days incubation), test media were administered with $20 \mathrm{ng} / \mathrm{ml}$ EGF, $0.1 \mathrm{~nm}$ R 1881 , $10 \mu \mathrm{M}$ Casodex and $300 \mathrm{~nm}$ AG1478. Another 3 days later (3 days incubation), these media were refreshed, and after 6 days of incubation, cells were washed twice in PBS before being lysed in $1 \mathrm{M} \mathrm{NaOH}$ (Blok et al. 2003). The DNA content was measured in a diluted ( $150 \mu$ sample $+850 \mu 1 \mathrm{H}_{2} \mathrm{O}$ ) sample by determination of OD 260. As a control $150 \mathrm{mM} \mathrm{NaOH}$ was measured and results are represented as percentage of OD260 of cells after 0 days of incubation. The experiments were performed in quadruple and repeated three times.

\section{RNA isolation and Northern blotting}

Total RNA was extracted by lysing cells in a solution containing $3 \mathrm{M}$ lithium chloride and $6 \mathrm{M}$ urea. DNA was sheared using a Ultra-Turax homogenizer at $100000 \mathrm{~g}$ (Ika-Werke, Staufen, Germany), the solution was cooled for $18 \mathrm{~h}$ at $4{ }^{\circ} \mathrm{C}$, and RNA was precipitated at $100000 \mathrm{~g}$ for $25 \mathrm{~min}$. and the pellet was dissolved in ES $(0.1 \%$ SDS, $0.2 \mathrm{mM}$ EDTA), and RNA was extracted with phenol/chloroform and chloroform.
Total RNA was precipitated in ethanol containing $0.16 \mathrm{M}$ sodium acetate. Purified RNA was elecrophoresed on a denaturing gel and blotted onto hybond $\mathrm{N}$ membrane (Amersham, Arlington Heights, IL, USA). The blots were fixed using u.v. and pre-hybridized for $1 \mathrm{~h}$ at $42{ }^{\circ} \mathrm{C}$ in a solution containing $45 \%$ formamide, $5 \times$ SCC, $0.5 \%$ SDS, $10 \%$ Denhardt's solution, $10 \mathrm{mM}$ phosphate buffer, $15 \%$ dextran sulfate and $100 \mathrm{mg} /$ liter herring sperm DNA. Labeled cDNA probes (random labelled with $\left[{ }^{32} \mathrm{P}\right] \mathrm{dATP}$; Amersham) were added to this solution, and hybridisation was allowed for 18-24 h at $42{ }^{\circ} \mathrm{C}$. Blots were washed for $2 \times 15 \mathrm{~min}$. at $55^{\circ} \mathrm{C}$ in a solution containing $0.5 \times \mathrm{SCC}$ and $0.25 \%$ SDS and exposed to a phosphor-imaging screen at room temperature for $24 \mathrm{~h}$ and scanned using a Typhoon phosphor imager (Amersham Biosciences).

\section{Results}

Androgen-dependent (FGC) and androgen-independent (LNO) human LNCaP prostate cancer cell lines were treated with the synthetic androgen R1881 $(0.1 \mathrm{~nm})$ or EGF $(20 \mathrm{ng} / \mathrm{ml})$ for $0,1.5,12,24$ or $72 \mathrm{~h}$ in medium depleted of endogenous steroids $(5 \% \mathrm{v} / \mathrm{v}$ DCC-FCS). After treatment, total RNA was isolated and gene expression was measured using comprehensive oligoarrays. Using the Rosetta Resolver Gene Expression Data Analysis System and the Microsoft Excel program, up- or down-regulated genes were identified. Genes with a $P$ value of $\leq 0.05$ and a changed expression of at least 2-fold in at least one data point, were defined as regulated. Because the oligoarray data obtained using RNA isolated from $12 \mathrm{~h}$ of treatment of FGC cells with EGF was considered to be of poor quality, inconsistent data from this array were left out of the present analysis.

\section{Differences in gene expression between androgen-dependent and androgen- independent LNCaP cell lines under non-hormone-stimulated conditions}

Androgen-dependent FGC and androgen-independent LNO cell lines originate from the same patient sample and the same genetic background (van Steenbrugge et al. 1991). These cell lines represent a model, where FGC cells need androgens or growth factors or both to proliferate (are androgen-dependent), while LNO cells have progressed and proliferate without further hormonal substitutions (are androgen-independent). This cellular difference leads to at least two questions. First, since androgen-independent LNO cells do not require added androgens or EGF for growth, to what 
extent are the associated signal transduction pathways constitutively activated? Second, do differentially expressed cell cycle genes play a role in androgenindependent growth of LNO cells?

To assess constitutive differences between the two cell lines, all non-hormone-stimulated data from androgen-dependent FGC cells were compared with all non-hormone-stimulated data from androgenindependent LNO cells. In practice, this implies that the average of all Cy5-data for over 17000 genes on the arrays were compared for each cell line. Transcripts for which the S.D. was higher than $25 \%$ of the average were excluded from this analysis. To verify the quality of collected data, to be able to compare the cell lines, several tests were conducted. The average Cy5 signals in FGC cells and in LNO cells showed a normal distribution, and signal intensities of positive and negative controls on the arrays were no more that 1.4-fold different. Furthermore, known differentially expressed genes like TRPS1, REPS2, B-cell translocation gene 1 (Chang et al. 1997), TMEFF2 (Gery et al. 2002), vimentin (Singh et al. 2003), CDC2 (Kallakury et al. 1999), IGFBP2 (Bubendorf et al. 1999) and the AR (Balk 2002) were indeed detected as differentially expressed between the two cell lines (not shown).

It was observed that 1350 out of 6702 expressed genes that met the restrictions were differentially expressed between the two non-hormone-stimulated cell lines; in androgen-independent LNO cells 848 transcripts were expressed higher and 502 transcripts were expressed lower, as compared with androgendependent FGC cells (Fig. 1). Because LNO cells proliferate when cultured under non-hormone-stimulated circumstances and the androgen-dependent FGC cells are then inhibited in growth, it is expected that this growth difference will be reflected in the profiles of gene expression.

To determine whether androgen- or EGF-regulated pathways are constitutively activated, potential androgen or EGF target genes were compared with the cohort of differentially expressed genes in the nonhormone stimulated situation. Androgen or EGF target genes were defined as genes with a changed expression of at least 2-fold in at least one data point after EGF or androgen exposure to FGC cells. Approximately $21 \%$ (181 out of 848 ) of the genes with a 2-fold higher expression in LNO cells (Fig. 1A, grey area) were found to be up-regulated by R1881, EGF, or both in FGC cells. Of the genes with a 2-fold lower expression in LNO cells compared with FGC (Fig. 1A, white area) approximately $14 \%$ (70 out of 502) were also down-regulated by R1881, EGF, or both in FGC cells (Fig. 1A). It is suggested that
A
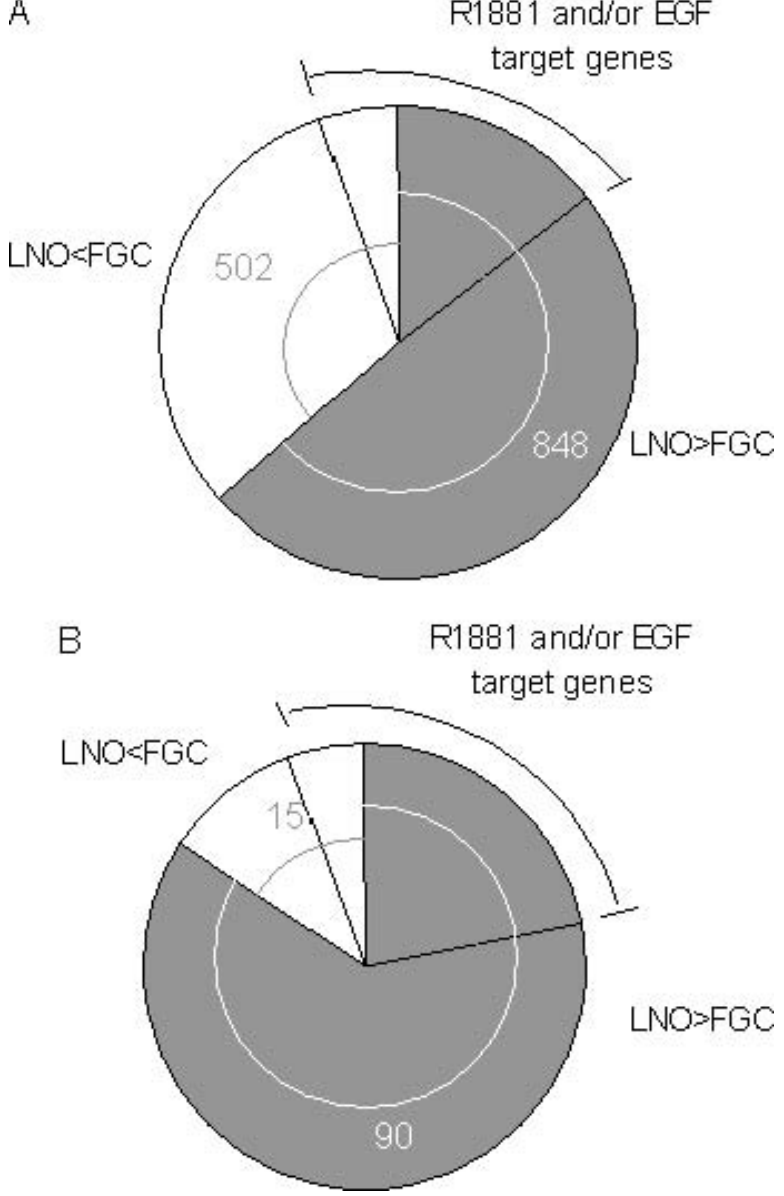

Figure 1 Differential gene expression between androgendependent (FGC) and androgen- independent (LNO) LNCaP cell lines. Number of genes differentially expressed between LNO and FGC cells. Androgen (R1881) and EGF target genes are indicated within these differential genes. 848 genes are at least two-fold higher expressed in LNO cells as compared with FGC cells. 502 genes are at least two-fold lower expressed in LNO cells as compared with FGC cells. Number of differentially expressed genes between LNO and FGC cells involved in proliferation. R1881 and EGF target genes are indicated within these proliferation genes. 90 proliferation-involved genes are at least two-fold higher expressed in LNO cells as compared with FGC cells. 15 proliferation-involved genes are at least two-fold lower expressed in LNO cells as compared with FGC cells. The filled segments represent transcripts that are higher expressed in LNO compared with FGC cells (LNO>FGC), and the open segments represent transcripts that are lower expressed in LNO cells compared with FGC cells $(\mathrm{LNO}<\mathrm{FGC})$.

approximately $20 \%$ of the identified differentially expressed genes are differentially expressed because androgen- and EGF-signalling is constitutively activated in LNO cells (Fig. 1A). Therefore, the capacity 
of androgen-independent cells to proliferate without androgenic stimulation might be caused in part by constitutive activation of androgen- and EGF-signalling.

Next, to assess the possible role of differentially expressed cell cycle genes, the known functions of all genes that were differentially expressed between nonhormone-stimulated cell lines were determined using the annotation tool GO-MAPPER that was developed by Smid and Dorssers (2004). This program categorizes genes into the different levels of the geneontology hierarchy (www.geneontology.org/doc/ GO.doc.html). It was observed that of the annotated genes (606 could be annotated) that were higher expressed in LNO cells, $31 \%$ were categorized as being involved in cell growth and maintenance (of which $15 \%$ were involved in cell proliferation), $59 \%$ in metabolism and $10 \%$ in cell communication. Genes with a two-fold lower expression in LNO cells were also categorized, and the result displayed more genes involved in cell communication $(26 \%)$ and less in cell proliferation $(5 \%)$.

In total 105 'proliferation-annotated' genes (Fig. 1B) were differentially expressed between androgendependent FGC and androgen-independent LNO cell lines. Interestingly, 29 of the differentially expressed genes appeared to be androgen- or EGF-regulated (Fig. 1B). These results further strengthen the hypothesis that androgen-independent cells may partly regulate proliferation by constitutive activation of androgen- or EGF-signalling pathways, or both.

\section{Androgen- and EGF-regulated genes in androgen-dependent and androgen- independent LNCaP cell lines}

Androgen-dependent FGC cells need steroid hormones or growth factors to proliferate, whereas androgenindependent LNO cells proliferate through endogenous stimulation of growth. Comparison and analysis of androgen- and EGF-regulated genes in both cell lines provides information about the extent to which signal transduction pathways converge to stimulate growth in androgen-dependent FGC cells and androgenindependent LNO cells.

It was observed that there is much overlap between androgen- and EGF-regulated genes in both cell lines. In androgen-dependent FGC cells, at least $40 \%$ of the genes that are regulated by $\mathrm{R} 1881$ are also regulated by EGF (Fig. 2; Table 1), indicating that R1881 and EGF stimulate partly the same cellular processes. Most $(97 \%)$ of these overlapping genes are regulated in the same direction, either up or down (Table 1). In LNO cells the overlap between R1881 and EGF up-regulated

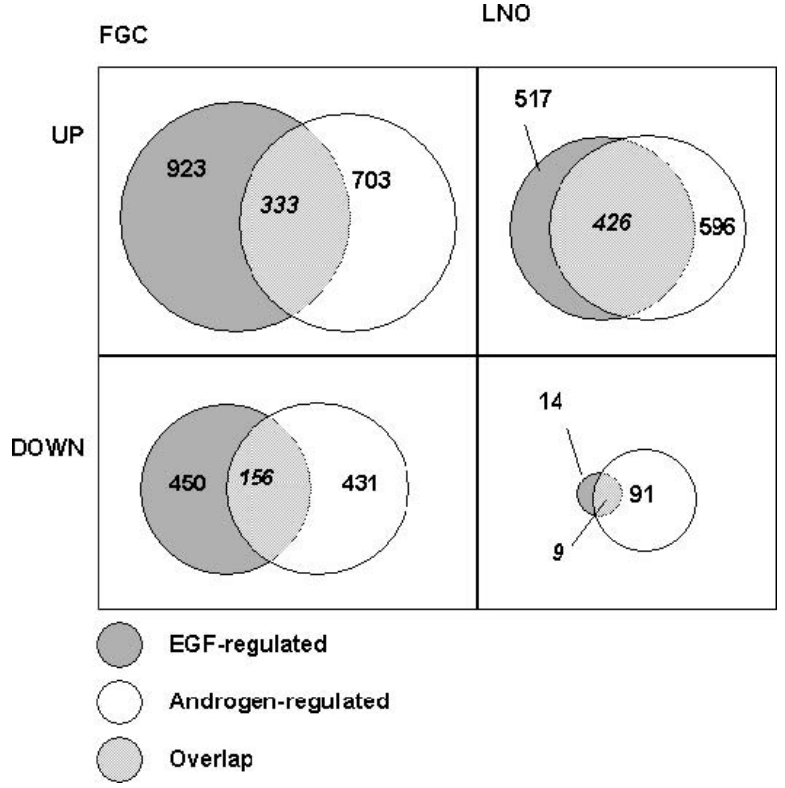

Figure 2 Number of identified androgen- and EGF-regulated genes in FGC and LNO cell lines. The number of androgenregulated transcripts is presented in white and EGF-regulated genes in grey. The number of genes regulated by both are shown in the overlapping fragments and are indicated in italics. The upper two pictures show up-regulated genes, the lower two down-regulated genes. Genes regulated in FGC cells are on the left, genes regulated in LNO cells are on the right.

genes is much larger, although the absolute numbers are in the same range as for FGC cells (Fig. 2; Table 1). Almost $75 \%$ of androgen up-regulated genes in LNO cells are also EGF up-regulated in these cells. This may indicate that, in androgen-independent LNO cells, EGF receptor signalling has made androgenic signalling partly redundant. Therefore, instead of androgens, locally produced EGF may act as a primary mitogen for these LNO cells.

To assess this hypothesis in a biological setting, proliferation assays were performed. FGC and LNO cells were cultured in the presence or absence of R1881, EGF, and/or specific inhibitors of AR action (Bicalutamide) or EGF receptor signalling (AG1478) for 6 days. Bicalutamide is an anti-androgen that inhibits the transcriptional activity of the AR in LNCaP cells (Veldscholte et al. 1992). AG1478 is a highly specific inhibitor of the EGF receptor that attenuates EGF signalling in LNCaP cells (Guo et al. 2000). It was observed that androgen-dependent FGC cells showed a very low proliferation rate during the time frame of the experiment in the non-hormone-stimulated situation, while the androgen-independent LNO cells showed a 6-fold increase in cell growth. Furthermore, 
Table 1 Number of genes up- or down-regulated by R1881 or EGF or both in FGC or LNO cells or both

\begin{tabular}{|c|c|c|c|c|c|c|c|c|c|}
\hline & & $\begin{array}{c}\text { up } \\
\text { FGC R1881 }\end{array}$ & $\operatorname{up}_{\text {FGC EGF }}$ & $\begin{array}{c}\text { up } \\
\text { LNO R1881 }\end{array}$ & $\operatorname{up}_{\text {LNO EGF }}$ & $\begin{array}{c}\text { down } \\
\text { FGC R1881 }\end{array}$ & $\begin{array}{c}\text { down } \\
\text { FGC EGF }\end{array}$ & $\begin{array}{c}\text { down } \\
\text { LNO R1881 }\end{array}$ & $\begin{array}{c}\text { down } \\
\text { LNO EGF }\end{array}$ \\
\hline up & FGC R1881 & 703 & 333 & 235 & 210 & & & & \\
\hline up & FGC EGF & & 923 & 381 & 379 & 11 & & & \\
\hline up & LNO R1881 & & & 596 & 426 & 1 & 1 & & \\
\hline up & LNO EGF & & & & 517 & 1 & 0 & 0 & \\
\hline down & FGC R1881 & & & & & 431 & 156 & 23 & 5 \\
\hline down & FGC EGF & 8 & & & & & 450 & 28 & 8 \\
\hline down & LNO R1881 & 1 & 4 & & & & & 91 & 9 \\
\hline down & LNO EGF & 1 & 0 & 0 & & & & & 14 \\
\hline
\end{tabular}

The number of genes regulated at least two-fold with a $P$ value $\leq 0.05$ in at least one time point by androgen (R1881) or EGF or both, in FGC cells or LNO cells or both.

upon culture of FGC cells in the presence of R1881 or EGF, cell growth was increased by 3 -fold or 2.2-fold, respectively. When both compounds were added together, an additive effect was observed (4.4-fold), indicating separate pathway usage by androgens and EGF in the androgen-dependent FGC cell line. In contrast to these observations, R1881 had only a minor effect on growth of LNO cells (Fig. 3; 1.4-fold on average), while EGF substitution, alone or in combination with R1881, had no effect on the growth of these cells.

When stimulation of growth by the two hormones (either separate or combined) was restrained by specific inhibitors (Bicalutamide or AG1478), it was observed that these compounds act as expected in androgendependent FGC cells. In androgen-independent LNO cells, however, the antiandrogen Bicalutamide inhibits only androgen signalling, while hardly any effect was observed due to the EGF receptor inhibitor AG1478 (Fig. 3). So, despite the fact that many proliferationannotated genes are regulated by androgens and EGF and are higher expressed in the androgen-independent LNO cell line, inhibition of EGF signalling at receptor level hardly affects growth of this cell line. Therefore, it is hypothesized that, in androgen-independent LNO cells, parts of the proliferation machinery are constitutively activated through mutations, deletions or amplifications of key genes acting down-stream from the androgen or EGF receptors, or through autonomous activation of other signalling pathways.

Interestingly, in the prostate cancer cell lines described herein, we found 56 genes involved in PI3Kinase pathway signalling to be differentially expressed between the two lines in the non-hormonestimulated situation using the DAVID pathway

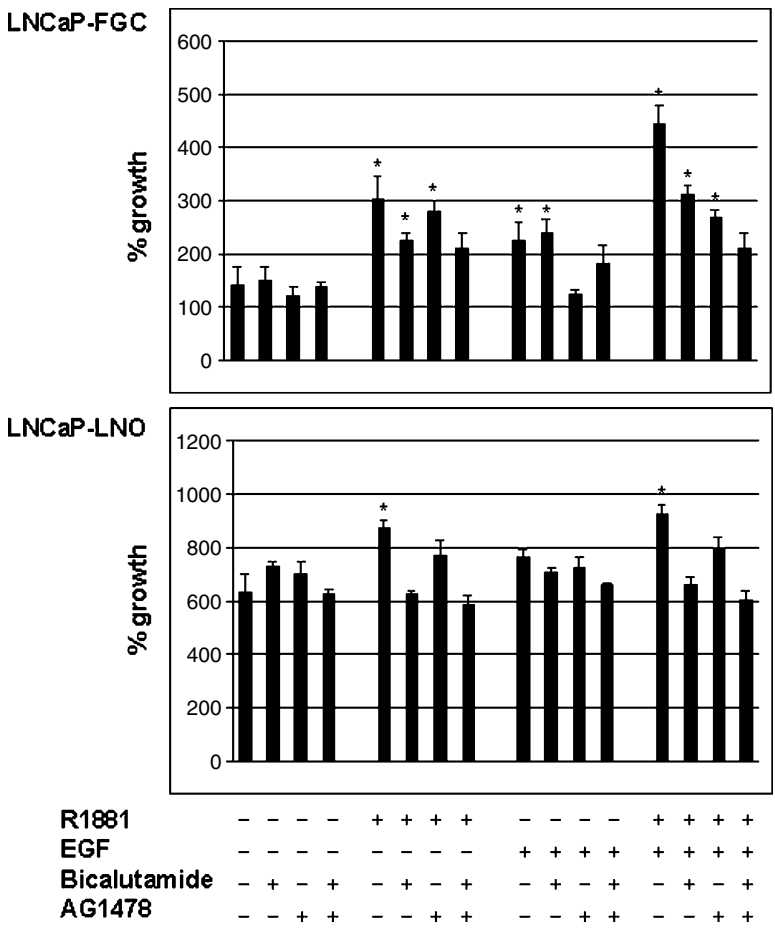

Figure 3 Regulation of growth of FGC and LNO cells by R1881, EGF, bicalutamide and AG1478. Cells were incubated with $20 \mathrm{ng} / \mathrm{ml}$ EGF, $0.1 \mathrm{~nm}$ R1881, $10 \mu \mathrm{M}$ bicalutamide and $300 \mathrm{~nm}$ AG1478 in the indicated combinations. After 6 days cells were harvested in $1 \mathrm{M} \mathrm{NaOH}$ and OD260 values were measured in diluted samples. Growth is expressed as a percentage of the OD 260 value at the start of the incubations. The experiments were conducted in 24 well plates and each measurement is the average of four wells + / - S.D. Results shown are representative of an experiment performed three times. All control incubations were performed in the presence of vehicle $(0.1 \%$ ethanol). Differences between control and treated samples were statisctically analysed with a paired-sampled $t$-test $\left({ }^{*} P<0.01\right)$. 


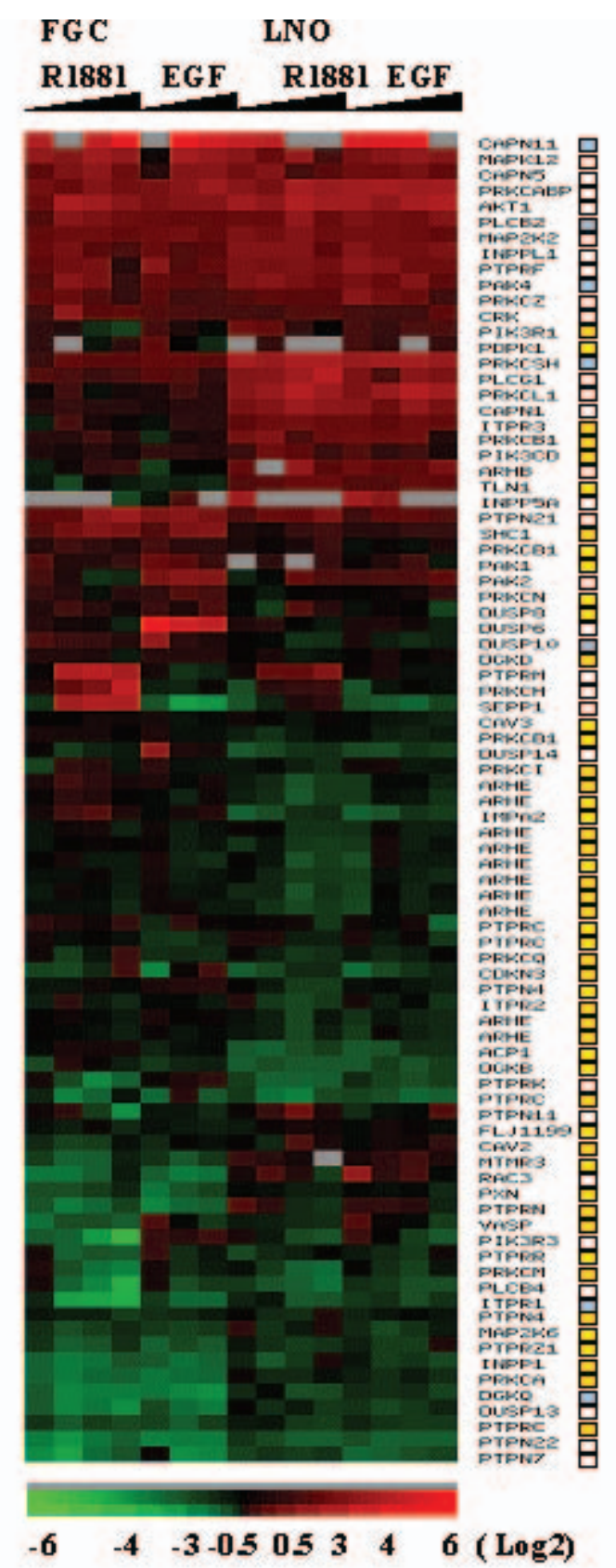

\section{ㅁ Differentially express ed gene \\ $\square$ Differentially express ed and regulated gene ㅁ Regulated gene}

Figure 4 Transcriptional regulation of genes involved in PI3Kinase signalling. Hierarchical clustering with uncentered distance measure of all PI3Kinase-involved transcripts that are regulated either by $\mathrm{R} 1881$ or EGF at least two-fold and in at least one time point, or are differentially expressed between FGC and LNO. Whether the transcripts are regulated (white boxes), differentially expressed (yellow boxes) or both (blue boxes), is indicated on the right. discovery tool. Of these 56 differential genes, 7 were androgen- or EGF-regulated. Another 29 genes were androgen- or EGF-regulated but not differentially expressed (Fig. 4). The PI3Kinase pathway is involved in prostate cancer progression and is essential for survival of LNCaP cells in an androgen-deprived environment (Lin et al. 1999). Therefore, regulation and expression differences of the PI3Kinase pathway between FGC and LNO cells were assessed by screening phosphorylated AKT kinase expression in these cells after stimulation by EGF or androgen. It was observed that AKT kinase was highly phosphorylated in both cell lines in the present non-hormone stimulated situation, but expression of phosphorylated AKT in FGC was twice as high as its expression in LNO. Addition of either R1881 or EGF had no effect on activation or expression levels of AKT kinase in both cell lines (data not shown). This indicates that the PI3Kinase pathway is constitutively activated in both cell lines, and is therefore not responsible for the proliferative advantage of androgen-independent prostate cancer cells over androgen-dependent prostate cancer cells.

\section{Hierarchical clustering of genes, differentially regulated between androgen-dependent and androgen-independent LNCaP cell lines}

So far, differences between androgen-dependent FGC and androgen-independent LNO cell lines in a non-hormone-stimulated situation, and the overlap between androgen and EGF signalling for these two cell lines, was analysed. As a subsequent step, we aimed to identify regulated genes that may contribute to functional differences between the two cell lines.

First, all genes that were regulated in at least one of the arrays were analysed using hierarchical clustering at www.ep.ebi.ac.uk/EP/EPCLUST/ (Fig. 5A). Some highly androgen- or EGF-regulated genes and their positions in the clusters are depicted (Fig. 5A) and their regulation confirmed by northern blotting (Fig. 5B). The black bars to the left of the figure indicate clusters for which gene regulation in LNO cells is clearly different from gene regulation in FGC

Samples analysed are represented by columns and shown from left to right are: FGC cells, treated with R1881 $(0.1 \mathrm{nM})$ for $1.5,12,24$ or $72 \mathrm{~h}$; FGC cells treated with EGF $(20 \mathrm{ng} / \mathrm{ml})$ for $1.5,24$ or $72 \mathrm{~h}$; LNO cells treated with R1881 $(0.1 \mathrm{nM})$ for $1.5,12,24$ or $72 \mathrm{~h}$; LNO cells treated with EGF $(20 \mathrm{ng} / \mathrm{ml})$ for $1.5,12,24$ or $72 \mathrm{~h}$. Each row represents a single transcript and red and green represent up- and down-regulation, respectively (see scale). 

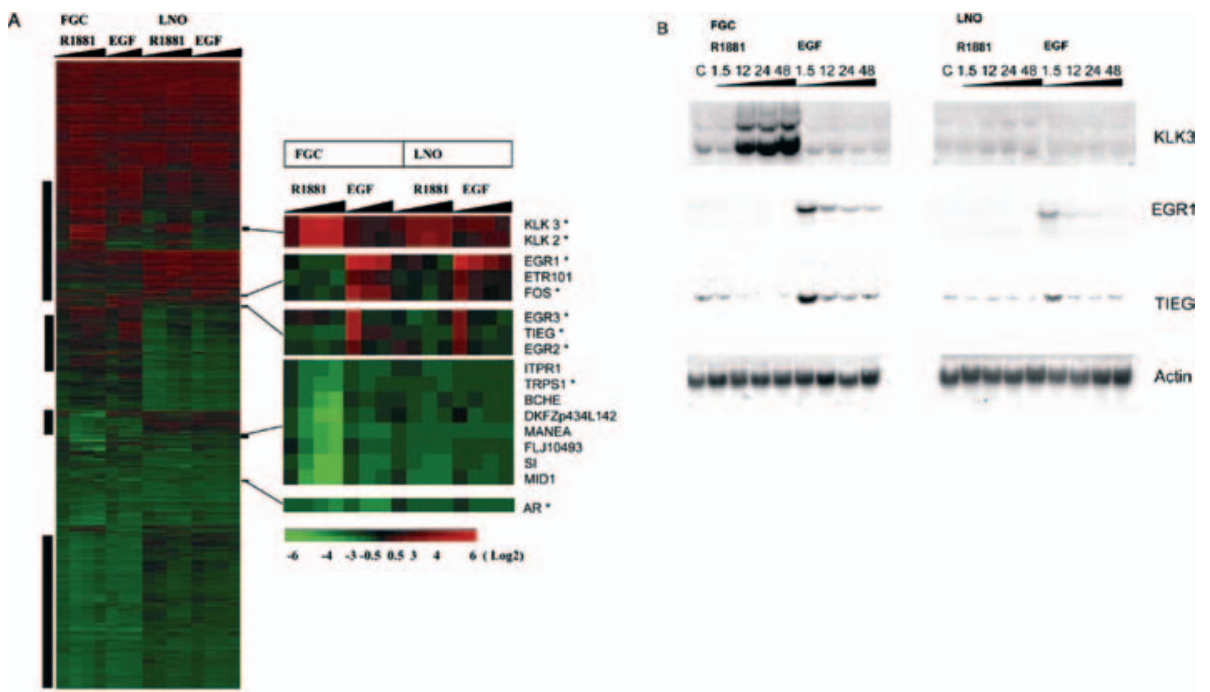

Figure 5(A) Transcriptional program activated by R1881 or EGF in FGC or LNO cells. Samples analysed and shown from left to right are: FGC cells treated with R1881 $(0.1 \mathrm{nM})$ for $1.5,12,24$ or $72 \mathrm{~h}$; FGC cells treated with EGF $(20 \mathrm{ng} / \mathrm{ml})$ for $1.5,24$ or $72 \mathrm{~h}$; LNO cells treated with R1881 $(0.1 \mathrm{nM})$ for $1.5,12,24$ or $72 \mathrm{~h}$; LNO cells treated with EGF $(20 \mathrm{ng} / \mathrm{ml})$ for $1.5,12,24 \mathrm{or}$ $72 \mathrm{~h}$. Hierarchical clustering with uncentered distance measure of all transcripts that are regulated either by R1881 or EGF at least two-fold and in at least one time point. Each row represents a single transcript and red and green represent up- and downregulation respectively (see scale). Black bars on the left indicate regions with differential gene expression signatures. Enlarged sections on the right indicate representative androgen- or EGF-regulated genes. Genes indicated with an asterisk have previously been reported as androgen- or EGF-regulated genes. (B) Northern blot analysis of FGC and LNO cells treated with R1881 or EGF. Expression of KLK3, EGR1 and TIEG was determined using specific cDNA probes. Equal amounts of RNA were loaded on each lane of the gel, as calculated using OD 260 measurements, and verified by determination of actin expression. Untreated samples are indicated with $\mathrm{C}$.

cells. Because we are interested in these gene clusters, ANOVA analysis was used to calculate which regulated genes were indeed differentially regulated between FGC and LNO cells.

Using the Rosetta Resolver Gene Expression Data Analysis System, 1138 genes were identified that were significantly differentially regulated between FGC and LNO (at least 2-fold and at least in one time point, by either EGF or androgen; $P$ value $<0.05$ ) (Fig. 6A). Within this dataset, two distinct clusters were formed that were either up-regulated in androgen-independent LNO cells and not regulated in androgen-dependent FGC cells (cluster A) or vice versa (cluster B). All transcripts, and transcripts specifically present in the two clusters, were annotated using GO-MAPPER (Smid \& Dorssers 2004) to a cellular function as indicated in Figure 6B. Interestingly, it was observed that cluster B contains more transcripts involved in proliferation and transport and less transcripts involved in transcription and communication as compared with cluster A. This suggests that cluster B contains genes that play a role in cell cycle control. To verify this, genes that were identified by Whitfield et al. (2002), which showed periodic variation during the cell cycle in HeLa cells were compared with the EGFor androgen-regulated genes from Figure 6A. Two hundred and two genes were found to overlap between the Whitfield data set (containing 1134 genes) and our 1138 regulated genes (Fig. 7). Of these 202 overlapping genes, 77 were present within cluster B. This number is remarkably high and indicates that cluster B indeed contains a subgroup of genes that may play a role in cell cycle control. Furthermore, since regulation by androgens and EGF of genes included in cluster B is very distinct between FGC and LNO cell lines, it is hypothesized that at least parts of the mechanisms that control the cell cycle are differentially regulated in androgen-dependent cells as compared with androgenindependent cells.

\section{Discussion}

Androgen-independent prostate cancer growth is the endpoint of tumour development, from normal growth of prostate cells that is induced and regulated by androgens to aberrant growth that is induced and maintained by other factors and mechanisms. These factors and mechanisms include sensitisation of the 


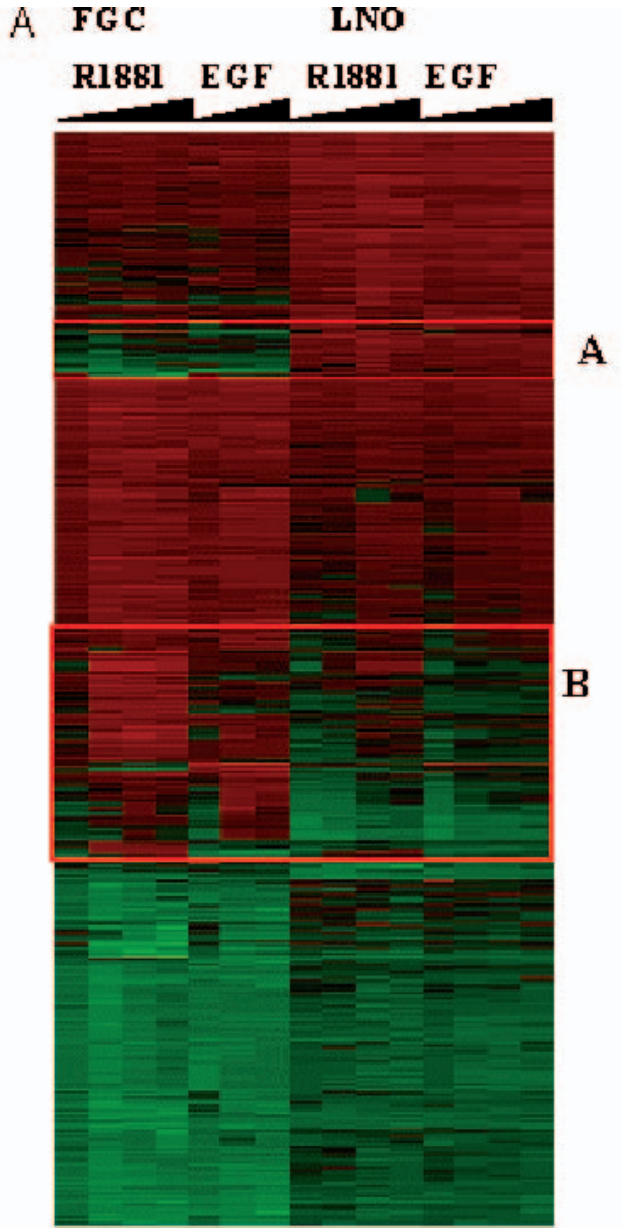

B

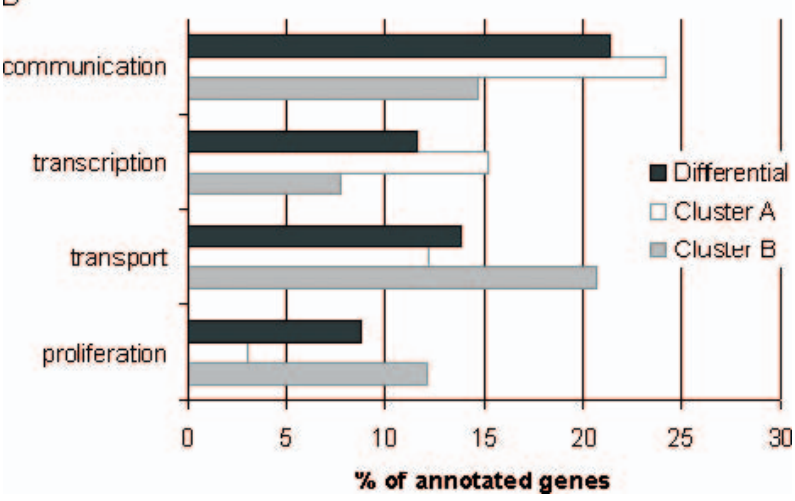

Figure 6(A) Differential transcription activation by R1881 or EGF in FGC or LNO cells. Hierarchical clustering with uncentered distance measure of all transcripts that are either regulated by $\mathrm{R} 1881$ or EGF at least two-fold in at least one time point and are differentially regulated between FGC and LNO as determined by ANOVA analysis with Rossetta Resolver, $P<0.05$. Indicated cluster A contains transcripts that are up-regulated in LNO cells but not regulated in FGC cells by androgen and/or EGF. Cluster B contains transcripts androgen receptor and activation of other signalling pathways, like cytokine and growth factor signalling or oncogenic signalling (Grossmann et al. 2001, Balk 2002).

The human prostate cancer cell line FGC is a model for androgen-dependent growth. In the current investigation we show that this cell line depends on either androgen or EGF for its growth. In contrast, growth of the LNO cell line, an androgen-independent sub-line of FGC is not dependent on androgen or EGF, and is influenced only to a minor extent by exposure to these hormonal factors. The FGC cell line harbours a mutation in the AR that changes the ligand specificity of the receptor for non-androgenic compounds like R5020, progesterone, estadiol and cyproterone acetate (Veldscholte et al. 1990). This mutation, however, does not change R1881-induced activation of the androgen receptor.

As a model for transition from androgen-dependent to androgen-independent prostate cancer growth, the above-mentioned two cell lines were explored. To identify differences between androgen-dependent and -independent growth, gene expression profiling was performed. Expression of both androgen and EGF receptors was approximately twice as high in FGC as compared with LNO cells, as determined by western blotting (not shown). This is in contrast with other androgen-independent cell line models like DU145 and PC3, which show high levels of EGF receptors (Oosterhoff et al. 2004). However, the expression of EGF receptors is not always up-regulated during the transition from androgen-dependent to androgenindependent prostate cancer. Only 29\% (31 out of 106) of prostate tumours showed increased EGF receptor expression (from negative to positive) in the course of transition (Hernes et al. 2004). Therefore, limited EGF receptor down-regulation as observed in LNO compared with FGC cells is not exceptional. Because many genes were activated by androgen and EGF in the androgen-independent LNO cell line, it was concluded that receptor expression levels were sufficient to generate a response. Various analyses of the results were executed, yielding information about differential signal transduction pathway usage by the two cell lines.

that are not regulated in LNO cells but up-regulated in FGC cells by androgen and/or EGF. (B) Annotation of all genes differentially regulated or present in cluster $A$ or $B$ as percentage of annotated genes in these groups. Annotation was performed using GO-MAPPER (Smid and Dorssers 2004). 


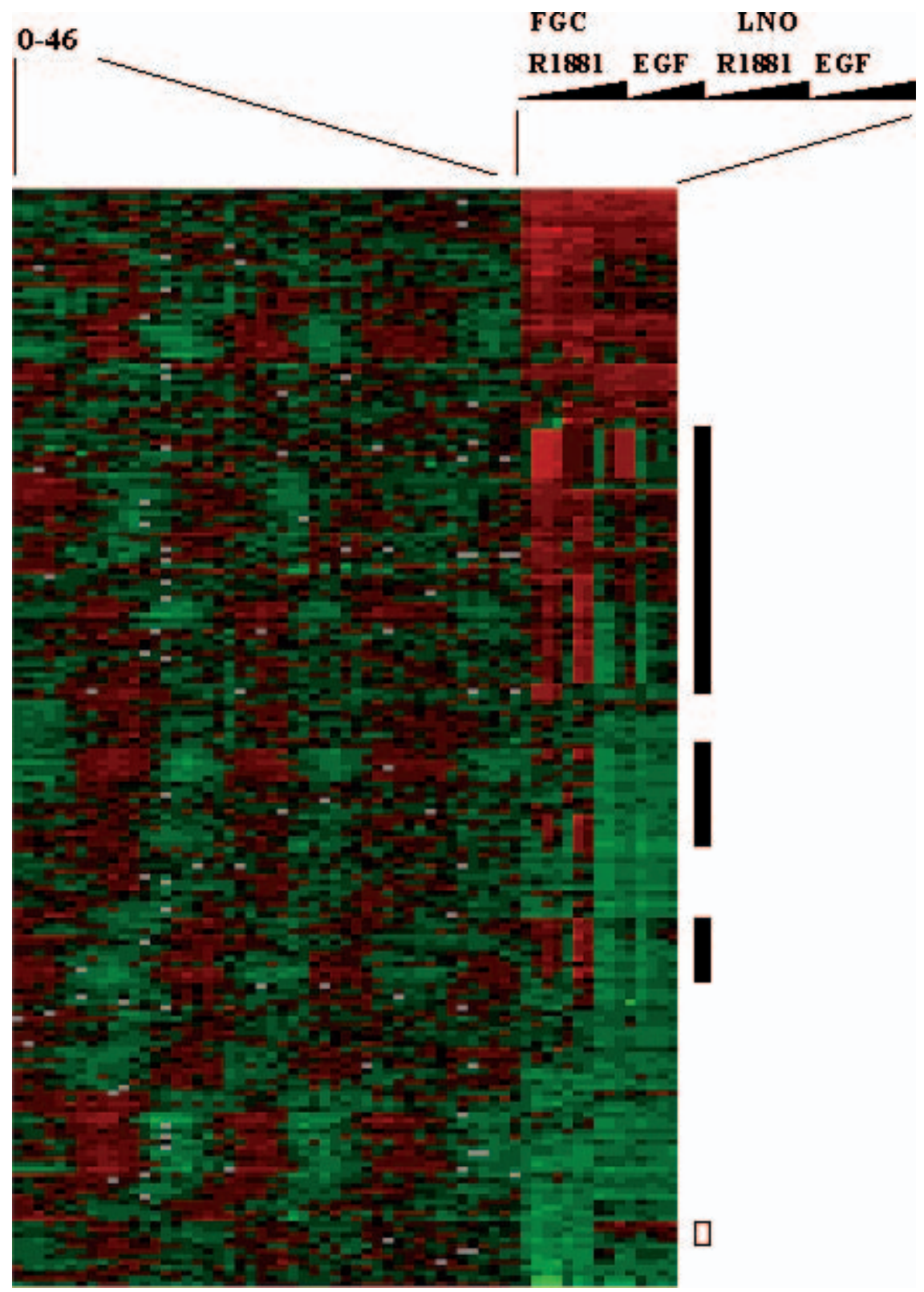

Figure 7 Analysis of transcripts periodically expressed in the cell cycle and regulated by androgen or EGF in FGC or LNO. Hierarchical clustering with uncentered distance measure of transcripts present in the Thy-Thy3 (0-46 h) cell cycle experiment described by Whitfield et al. (2002) and the present LNCaP experiment. Samples analysed are represented by columns and shown from left to right are: HeLa cells, sampled each hour until $46 \mathrm{~h}$ after synchronized release from cell cycle arrest; FGC cells treated with R1881 $(0.1 \mathrm{nM})$ for $1.5,12,24$ or $72 \mathrm{~h}$; FGC cells treated with EGF (20 ng/ml) for $1.5,24$ or $72 \mathrm{~h}$; LNO cells treated with R1881 $(0.1 \mathrm{nM})$ for $1.5,12,24$ or $72 \mathrm{~h}$; LNO cells treated with EGF $(20 \mathrm{ng} / \mathrm{ml})$ for $1.5,12,24$ or $72 \mathrm{~h}$. The regions indicated by black bars contain genes that are up-regulated in FGC and not regulated in LNO cells. The white bar indicates a small region representing genes for which this regulation is in a reverse manner.

Using the averages of the intensities of the reference samples, that represented a non-hormone-stimulated situation, a group of genes was defined that is differentially expressed between the androgen-dependent and the androgen-independent cell lines. This group includes a large number of androgen- and EGFregulated and/or proliferation-related genes. Possibly, constitutive activation of these specific clusters of genes in the androgen-independent cell line adds to the autonomous growth behaviour. The observations that 
the androgen-independent cells grew well on steroid hormone-free medium, and that the addition of R1881, EGF, an anti-androgen or EGF receptor-inhibitor had little effect on this growth further indicated the presence of a constitutive activated proliferation pathway. Furthermore, it is interesting to note that in LNO cells, the absolute number of EGF-regulated genes involved in proliferation is remarkably lower as compared with the number in FGC cells (29 in LNO, 67 in FGC).

Upon analysis of genes that were differentially regulated by R1881, EGF, or both it was observed that the overlap between EGF and R1881 activated genes is approximately $75 \%$. In the androgendependent FGC cells this number is much lower, since only $40 \%$ of EGF and androgen activated genes overlap. Whether the EGF receptor pathway and the AR pathway in androgen-independent LNO cells indeed show more crosstalk than in FGC could not be confirmed, since LNO cells hardly respond to specific anti-androgen (Bicalutamide) and EGF receptor signal inhibitor (AG1478). This last observation, however, does indicate that the proliferation machinery is constitutively activated through mutations, deletions or amplifications of key regulatory genes acting down-stream from the androgen or EGF receptors, or through activation of other signalling pathways.

A potential candidate pathway to induce proliferation in androgen-independent cells is the PI3Kinase pathway. It has previously been reported that, in LNCaP cells, the PI3Kinase pathway is constitutively active (Pfeil et al. 2004) and essential for survival in an androgen-deprived environment (Lin et al. 1999). It was observed that androgen ablation increased the activity of PI3Kinase and AKT during establishment of androgen-independent sublines of $\mathrm{LNCaP}$, and that addition of androgens blocked that effect (Graff et al. 2000, Murillo et al. 2001). It should also be mentioned, however that other reports do not described this difference in expression of PI3Kinase and AKT after long-term androgen ablation of FGC cells (Pfeil et al. 2004).

In the present study, it was observed that 56 PI3Kinase-annotated genes were differentially expressed between FGC and LNO cells and 36 PI3Kinase-annotated genes were androgen- or EGFregulated (of which seven genes are both differentially expressed and hormone-regulated). However, when we measured the activity of PI3Kinase by measuring phosphorylated AKT, constitutive activation of the PI3Kinase pathway in both cell lines was found, with the highest activity in FGC and no effect of either androgen or EGF addition. Constitutive active PI3Kinase could be an important determinant that prevents FGC cells from dying during androgen ablation, but the lower activity of the PI3Kinase pathway in LNO cells cannot explain the proliferative advantage of the androgen-independent cells. Therefore, other proliferation-inducing pathways must be activated in these cells, like the Ras/Raf/MAPK pathway. This pathway was not indicated by the DAVID pathway discovery tool but could be of great importance, since it is also indicated to be involved in prostate cancer progression (Culig 2004, Gregory et al. 2004).

Cluster-analysis of regulated genes resulted in the formation of groups of genes that showed differential regulation between FGC and LNO cells. Two groups were extremely different, either up-regulated by EGF and/or androgens in LNO and not regulated by EGF and/or androgens in FGC, or vice versa. A remarkably high number of genes involved in proliferation was found in the group that was up-regulated in FGC and not regulated in LNO cells. Furthermore, when compared with previously identified genes regulated during the cell cycle in HeLa cells (Whitfield et al. 2002), 77 cyclic genes were found to be up-regulated in FGC and not regulated in LNO. Up-regulation of these cell cycle regulated genes, specifically in FGC, could indicate that this asynchronous cell population contains many cycling cells after addition of androgens and/or EGF. If this is the case, then LNO cells should express many cell cycle regulated genes without addition of androgens or EGF, since these cells grow well under those circumstances. Indeed 138 genes from the Whitfield data-set were higher expressed in LNO when compared with FGC in the non-hormonestimulated situation. Furthermore, 33 out of these 138 transcripts were implicated in cancer, which also indicates that LNO cells possess a phenotype associated with proliferative tumour cells. Recently an interesting comparison was made between LNCaP cells inhibited in growth by methylseleninic acid (MSA) and periodically expressed cell cycle genes (Whitfield et al. 2002). Most cell cycle-involved genes $(74 \%)$ were found to be down-regulated in $\mathrm{LNCaP}$ cells that were inhibited in growth (Zhao et al. 2004). We found $60 \%$ of the cell cycle regulated genes to be up-regulated in FGC cells that were stimulated in growth by either R1881 or EGF.

Several genes previously reported and shown to be differentially expressed between FGC and LNO cells were confirmed with these microarray experiments. B-cell translocation gene 1, REPS2 and TRPS1 were determined by RNA differential display (Chang et al. 
1997) and also by these microarray analyses to be differentially expressed between FGC and LNO cells. Furthermore, EGF- or androgen-regulated genes like EGR1, TIEG and KLK3 were previously reported (Riegman et al. 1991, Blok et al. 1995) and confirmed here (Fig. 5B).

In summary, it is suggested that androgenindependent LNO cells can proliferate in the absence of androgenic stimulation, because firstly many cell cycle genes, including a number of androgen- and EGF-regulated genes, are constitutively activated; secondly the overlap between androgen receptor signalling and EGF receptor signalling pathways is very high $(80 \%)$ and thirdly other unknown signal transduction pathways have been activated and induce proliferation.

\section{Funding}

This work was supported by a grant from The Netherlands Organization for Health Research and Development (reg.nr. 903-46-179). There is no conflict of interest that would prejudice its impartiality.

\section{References}

Balk SP 2002 Androgen receptor as a target in androgenindependent prostate cancer. Urology 60 132-138, discussion 138-139.

Blok LJ, Grossmann ME, Perry JE \& Tindall DJ 1995 Characterization of an early growth response gene, which encodes a zinc finger transcription factor, potentially involved in cell cycle regulation. Molecular Endocrinology 9 1610-1620.

Blok LJ, De Ruiter PE, Kuhne EC, Hanekamp EE, Grootegoed JA, Smid-Koopman E, Gielen SC, De Gooyer ME, Kloosterboer HJ \& Burger CW 2003 Progestogenic effects of tibolone on human endometrial cancer cells. Journal of Clinical Endocrinology and Metabolism 88 2327-2334.

Brinkmann AO, Blok LJ, de Ruiter PE, Doesburg P, Steketee K, Berrevoets CA \& Trapman J 1999 Mechanisms of androgen receptor activation and function. Journal of Steroid Biochemistry and Molecular Biology 69 307-313.

Bubendorf L, Kolmer M, Kononen J, Koivisto P, Mousses S, Chen Y, Mahlamaki E, Schraml P, Moch H, Willi N, Elkahloun AG, Pretlow TG, Gasser TC, Mihatsch MJ, Sauter G \& Kallioniemi OP 1999 Hormone therapy failure in human prostate cancer: analysis by complementary DNA and tissue microarrays. Journal of the National Cancer Institute 91 1758-1764.

Chang GT, Blok LJ, Steenbeek M, Veldscholte J, van Weerden WM, van Steenbrugge GJ \& Brinkmann AO 1997 Differentially expressed genes in androgen-dependent and -independent prostate carcinomas. Cancer Research 57 4075-4081.

Connolly JM \& Rose DP 1990 Production of epidermal growth factor and transforming growth factor-alpha by the androgen-responsive LNCaP human prostate cancer cell line. Prostate 16 209-218.

Culig Z, Hobisch A, Cronauer MV, Radmayr C, Trapman J, Hittmair A, Bartsch G \& Klocker H 1994 Androgen receptor activation in prostatic tumor cell lines by insulinlike growth factor-I, keratinocyte growth factor, and epidermal growth factor. Cancer Research 54 5474-5478.

Culig Z 2004 Androgen receptor cross-talk with cell signalling pathways. Growth Factors 22 179-184.

Di Lorenzo G, Tortora G, D'Armiento FP, De Rosa G, Staibano S, Autorino R, D'Armiento M, De Laurentiis M, De Placido S, Catalano G, Bianco AR \& Ciardiello F 2002 Expression of epidermal growth factor receptor correlates with disease relapse and progression to androgen-independence in human prostate cancer. Clinical Cancer Research 8 3438-3444.

Djakiew D 2000 Dysregulated expression of growth factors and their receptors in the development of prostate cancer. Prostate 42 150-160.

Fiorelli G, De Bellis A, Longo A, Pioli P, Costantini A, Giannini S, Forti G \& Serio M 1991 Growth factors in the human prostate. Journal of Steroid Biochememistry and Molecular Biology 40 199-205.

Garbay C, Liu WQ, Vidal M \& Roques BP 2000 Inhibitors of Ras signal transduction as antitumor agents. Biochemical Pharmacology 60 1165-1169.

Gelmann EP 2002 Molecular biology of the androgen receptor. Journal of Clinical Oncology 20 3001-3015.

Gery S, Sawyers CL, Agus DB, Said JW \& HP Koeffler 2002 TMEFF2 is an androgen-regulated gene exhibiting antiproliferative effects in prostate cancer cells. Oncogene 21 4739-4746.

Graff JR, Konicek BW, McNulty AM, Wang Z, Houck K, Allen S, Paul JD, Hbaiu A, Goode RG, Sandusky GE, Vessella RL \& Neubauer BL 2000 Increased AKT activity contributes to prostate cancer progression by dramatically accelerating prostate tumor growth and diminishing p27Kip1 expression. Journal of Biological Chemistry 275 24500-24505.

Gregory CW, Fei X, Ponguta LA, He B, Bill HM, French FS \& Wilson EM 2004 Epidermal growth factor increases coactivation of the androgen receptor in recurrent prostate cancer. Journal of Biological Chemistry 279 7119-7130.

Grossmann ME, Huang H \& Tindall DJ 2001 Androgen receptor signalling in androgen-refractory prostate cancer. Journal of the National Cancer Institute 93 1687-1697.

Guo C, Luttrell LM \& DT Price 2000 Mitogenic signalling in androgen sensitive and insensitive prostate cancer cell lines. Journal of Urology 163 1027-1032.

Hayward SW, Rosen MA \& Cunha GR 1997 Stromalepithelial interactions in the normal and neoplastic prostate. British Journal of Urology 79 (Suppl 2) 18-26. 
Hernes E, Fossa SD, Berner A, Otnes B \& Nesland JM 2004 Expression of the epidermal growth factor receptor family in prostate carcinoma before and during androgen-independence. British Journal of Cancer $\mathbf{9 0}$ 449-454.

Hiramatsu M, Kashimata M, Minami N, Sato A \& Murayama M 1988 Androgenic regulation of epidermal growth factor in the mouse ventral prostate. Biochemy International 17 311-317.

Horoszewicz JS, Leong SS, Chu TM, Wajsman ZL, Friedman M, Papsidero L, Kim U, Chai LS, Kakati S, Arya SK \& Sandberg AA 1980 The LNCaP cell line-a new model for studies on human prostatic carcinoma. Progression in Clinical Biological Research 37 115-132.

Kallakury BV, Sheehan CE, Rhee SJ, Fisher HA, Kaufman RP Jr, Rifkin MD \& Ross JS 1999 The prognostic significance of proliferation-associated nucleolar protein p120 expression in prostate adenocarcinoma: a comparison with cyclins A and B1, Ki-67, proliferating cell nuclear antigen, and p34cdc2. Cancer 85 1569-1576.

Lin J, Adam RM, Santiestevan E \& Freeman MR 1999 The phosphatidylinositol 3'-kinase pathway is a dominant growth factor-activated cell survival pathway in LNCaP human prostate carcinoma cells. Cancer Research 59 2891-2897.

Murillo H, Huang H, Schmidt LJ, Smith DI \& Tindall DJ 2001 Role of PI3K signalling in survival and progression of LNCaP prostate cancer cells to the androgen refractory state. Endocrinology 142 4795-4805.

Nishi N, Oya H, Matsumoto K, Nakamura T, Miyanaka H \& Wada F 1996 Changes in gene expression of growth factors and their receptors during castration-induced involution and androgen-induced regrowth of rat prostates. Prostate 28 139-152.

Oosterhoff JK, Kuhne LC, Grootegoed JA \& Blok LJ 2004 EGF signalling in prostate cancer cell lines is inhibited by a high expression level of the endocytosis protein REPS2. International Journal of cancer 113 561-567.

Pfeil K, Eder IE, Putz T, Ramoner R, Culig Z, Ueberall F, Bartsch G \& Klocker H 2004 Long-term androgenablation causes increased resistance to PI3K/Akt pathway inhibition in prostate cancer cells. Prostate 58 259-268.

Riegman PH, Vlietstra RJ, van der Korput JA, Brinkmann AO \& Trapman J 1991 The promoter of the prostatespecific antigen gene contains a functional androgen responsive element. Molecular Endocrinology 5 1921-1930.

Robertson CN, Roberson KM, Herzberg AJ, Kerns BJ, Dodge RK \& Paulson DF 1994 Differential immunoreactivity of transforming growth factor alpha in benign, dysplastic and malignant prostatic tissues. Surgical Oncology 3 237-242.

Russell PJ, Bennett S \& Stricker P 1998 Growth factor involvement in progression of prostate cancer. Clinical Chemistry 44 705-723.
Scher HI, Sarkis A, Reuter V, Cohen D, Netto G, Petrylak D, Lianes P, Fuks Z, Mendelsohn J \& Cordon-Cardo J 1995 Changing pattern of expression of the epidermal growth factor receptor and transforming growth factor alpha in the progression of prostatic neoplasms. Clinical Cancer Research 1 545-550.

Schuurmans AL, Bolt J, Voorhorst MM, Blankenstein RA \& Mulder E 1988 Regulation of growth and epidermal growth factor receptor levels of $\mathrm{LNCaP}$ prostate tumor cells by different steroids. International Journal of Cancer 42 917-922.

Shaffer DR \& Scher HI 2003 Prostate cancer: a dynamic illness with shifting targets. Lancet Oncology 4 407-414.

Singh S, Sadacharan S, Su S, Belldegrun A, Persad S \& Singh G 2003 Overexpression of vimentin: role in the invasive phenotype in an androgen-independent model of prostate cancer. Cancer Research 63 2306-2311.

Smid M \& Dorssers LC 2004 GO-Mapper: functional analysis of gene expression data using the expression level as a score to evaluate Gene Ontology terms.

Bioinformatics $202618-2625$.

Turkeri LN, Sakr WA, Wykes SM, Grignon DJ, Pontes JE \& Macoska JA 1994 Comparative analysis of epidermal growth factor receptor gene expression and protein product in benign, premalignant, and malignant prostate tissue. Prostate 25 199-205.

van Steenbrugge GJ, CJ van Uffelen, Bolt J \& Schroder FH 1991 The human prostatic cancer cell line $\mathrm{LNCaP}$ and its derived sublines: an in vitro model for the study of androgen sensitivity. Journal of Steroid Biochemistry and Molecular Biology 40 207-214.

Veldscholte J, Ris-Stalpers JC, Kuiper GG, Jenster G, Berrevoets C, Claassen E, van Rooij HC, Trapman J, Brinkmann AO \& E Mulder 1990 A mutation in the ligand binding domain of the androgen receptor of human LNCaP cells affects steroid binding characteristics and response to anti-androgens. Biochemical and Biophysical Research Communications 173 534-540.

Veldscholte J, Berrevoets CA, Brinkmann AO, Grootegoed JA \& Mulder E 1992 Anti-androgens and the mutated androgen receptor of LNCaP cells: differential effects on binding affinity, heat-shock protein interaction, and transcription activation. Biochemistry $\mathbf{3 1}$ 2393-2399.

Wells A 1999 EGF receptor. International Journal of Biochemistry and Cell Biology 31 637-643.

Whitfield ML, Sherlock G, Saldanha AJ, Murray JI, Ball CA, Alexander KE, Matese JC, Perou CM, Hurt MM, Brown PO \& D Botstein 2002 Identification of genes periodically expressed in the human cell cycle and their expression in tumors. Molecular Biology of the Cell 13 1977-2000.

Wong YC \& Wang YZ 2000 Growth factors and epithelial-stromal interactions in prostate cancer development. International Reviews of Cytology 199 65-116. 
Yarden Y 2001 The EGFR family and its ligands in human cancer: signalling mechanisms and therapeutic opportunities. European Journal of Cancer 37 Suppl 3-8. Yeh S, Lin HK, Kang HY, Thin TH, Lin MF \& Chang C 1999 From HER2/Neu signal cascade to androgen receptor and its coactivators: a novel pathway by induction of androgen target genes through MAP kinase in prostate cancer cells. PNAS 96 5458-5463.

Zhao H, Whitfield ML, Xu T, Botstein D \& Brooks JD 2004 Diverse effects of methylseleninic acid on the transcriptional program of human prostate cancer cells. Molecular Biology of the Cell 15 506-519. 